\title{
Mutations in CYP2U1, DDHD2 and GBA2 genes are rare causes of complicated forms of hereditary spastic paraparesis
}

\author{
Andrea Citterio - Alessia Arnoldi - Elena Panzeri - Maria Grazia D'Angelo • \\ Massimiliano Filosto • Robertino Dilena • Filippo Arrigoni • Marianna Castelli • \\ Cristina Maghini - Chiara Germiniasi - Francesca Menni • Andrea Martinuzzi • \\ Nereo Bresolin • Maria Teresa Bassi
}

\begin{abstract}
Complicated hereditary spastic paraplegias (HSP) are a heterogeneous group of HSP characterized by spasticity associated with a variable combination of neurologic and extra-neurologic signs and symptoms. Among them, HSP with thin corpus callosum and intellectual disability is a frequent subtype, often inherited as a recessive trait (ARHSP-TCC). Within this heterogeneous subgroup, SPG11 and SPG15 represent the most frequent subtypes. We analyzed the mutation frequency of three genes
\end{abstract}

A. Citterio and A. Arnoldi contributed equally to this work.

A. Citterio . A. Arnoldi E. Panzeri . M. Castelli

N. Bresolin. M. T. Bassi (\&)

Laboratory of Molecular Biology, Scientific Institute IRCCS

Eugenio Medea, Via D. L. Monza 20, Bosisio Parini,

23842 Lecco, Italy

e-mail: mariateresa.bassi@bp.lnf.it;

mariateresa.bassi@lanostrafamiglia.it

M. G. D'Angelo

Neuromuscular Disorders Unit, Scientific Institute IRCCS

Eugenio Medea, Bosisio Parini, 23842 Lecco, Italy

M. Filosto

Clinical Neurology, Section for Neuromuscular Diseases and Neuropathies, University Hospital "Spedali Civili”, Brescia, Italy

R. Dilena

Unit of Clinical Neurophysiology, Fondazione IRCCS Ca'

Granda Ospedale Maggiore Policlinico, Milan, Italy

F. Arrigoni

Neuroimaging Unit, Scientific Institute IRCCS Eugenio Medea, Bosisio Parini, 23842 Lecco, Italy associated with early-onset forms of ARHSP with and without TCC, CYP2U1/SPG56, DDHD2/SPG54 and GBA2/SPG46, in a large population of selected complicated HSP patients by using a combined approach of ditional-based and amplicon-based high-throughtpat pooled-sequencing. Three families with mutations were identified, one for each of the genes analyzed. Novel homozygous mutations were identified in CYP2U1 (c.1A[C/p.Met1?) and in GBA2 (c.2048G[C/ p.Gly683Arg), while the homozygous mutation found in DDHD2 (c.1978G[C/p.Asp660His) had been previously reported in a compound heterozygous state. The phenotypes associated with the CYP2U1 and DDHD2 mutations overlap the SPG56 and the SPG54 subtypes, respectively,

\section{Maghini . C. Germiniasi}

Neurorehabilitation Unit, Scientific Institute IRCCS Eugenio Medea, Bosisio Parini, 23842 Lecco, Italy

F. Menni

Department of Physiopathology and Transplantation, Università di Milano, Fondazione IRCCS Ca' Granda Ospedale Maggiore Policlinico, Pediatric Clinic 1, Milan, Italy

\section{A. Martinuzzi}

Conegliano Research Center, Scientific Institute IRCCS Eugenio Medea, Conegliano, Italy

N. Bresolin

Neurology Unit, Department of Physiopathology and

Transplantation, Dino Ferrari Centre, IRCCS Ca' Granda, Ospedale Maggiore Policlinico Foundation, Universita' di Milano, Milan, Italy 
with few differences. By contrast, the GBA2 mutated patients show phenotypes combining typical features of both the SPG46 subtype and the recessive ataxia form, with marked intrafamilial variability thereby expanding the spectrum of clinical entities associated with GBA2 mutations. Overall, each of three genes analyzed shows a low mutation frequency in a general population of complicated HSP $\ \%$ for either CYP2U1 or DDHD2 and approximately $2 \%$ for GBA2). These findings underline once again the genetic heterogeneity of ARHSP-TCC and the clinical overlap between complicated HSP and the recessive ataxia syndromes.

Keywords Amplicon-based targeted resequencing . Spastic paraparesis . CYP2U1. DDHD2 . GBA2

\section{Introduction}

Hereditary spastic paraplegias (HSP) constitute a group of clinically and genetically heterogeneous neurodegenerative diseases characterized by progressive spasticity and weakness of the lower limbs due to retrograde axonal degeneration of the corticospinal tracts and posterior columns [1-3].

Complicated forms of HSP are characterized by the presence of variable combinations of neurologic features such as ataxia, peripheral neuropathy, intellectual disability, epilepsy or extraneurologic signs in addition to spasticity [4]. HSP with thin corpus callosum (HSP-TCC) and intellectual disability is a frequent subtype of complicated HSP, often inherited as an autosomal recessive trait (ARHSPTCC) $[5,6]$. It is clinically characterized by slowly progressive spastic paraparesis and mental deterioration mainly beginning before the second decade of life. A wide genetic heterogeneity characterizes this subgroup of complicated HSP with several genes identified such as SPG21, SPG11, ZFYVE26/SPG15, FA2H, AP4S1, AP4M1, AP4B1 [6], and more recently CYP2U1 [7], DDHD2 [8], TECPR2 [9] and GBA2 $[10,11]$. The two genes most frequently mutated in these forms are SPG11 and ZFYVE26/SPG15, accounting for $20 \%$ and $3 \%$ of the cases, respectively, with almost indistinguishable clinical phenotypes [12-14]. With regard to the most recently identified genes CYP2U1, DDHD2, TECPR2 and GBA2, both mutation frequencies and the full range of associated phenotypes still need to be defined. We tried to fill this gap by screening for mutations a cohort of 150 patients with recessive or sporadic complicated spastic paraparesis for CYP2U1 and DDHD2 mutations. Forty-six of them were also screened for GBA2 mutations. Herein, we report the result of the screening with the mutations identified in each of the three genes tested and the clinicalgenetic and diagnostic implications of these findings.
Patients and methods

\section{Patients}

We studied the index subjects of 150 HSP families (140 of Italian origin and 10 from North Africa) with slowly progressive complicated spastic paraparesis and intellectual disability. Ninety patients were sporadic while 60 were from recessive families. A variable combination of axonal neuropathy and signs of lower motor neuron degeneration were present in almost all of them. The majority of the patients $(n=125)$ showed TCC either isolated or with a variable pattern of white matter abnormalities (WMA), cerebellar and cerebral atrophy at the MRI analysis, by contrast, 25 patients had a normal MRI. Symptoms onset was between 0 and 18 years of age. Clinical data of the patients were obtained by clinical evaluation by the referring neurologist, based on the Harding criteria [15] for the definition of the clinical status and, thus, excluding any possible alternative cause of spastic paraplegia. The Intelligence quotient (IQ) evaluated through the Wechsler Intelligence Scales for Children or for Adult along with a detailed neuropsychological evaluation (Wechsler Memory Scale), was available for $98 \%$ of the cases. All families had been previously screened for mutations in SPG7, SPG11, SPG15, SPG21 and SPG35 with negative results. ALS2, SIGMA1R and ERLIN2 mutations were also excluded in all patients with normal MRI. SPG4 and SPG3A mutations were also excluded in all patients with apparently sporadic occurrence of the disease.

\section{Genetic analysis}

We obtained blood samples and clinical data from affected and unaffected subjects of the pedigree under a protocol of informed consent approved by the Ethics Committee of the E. Medea Scientific Institute. DNA was purified by using a standard high-salt purification method.

Mutation analysis of the coding exons of CYP2U1, DDHD2, GBA2 genes was performed by using a combined approach of Sanger sequencing and targeted resequencing. In detail, CYP2U1 and DDHD2 coding exons were firs directly sequenced in 104 patients by the Sanger method. Sequences were prepared with a Big Dye Terminator sequencing Kit (version 3.1 Applied Biosystem, Foster City, USA) and run on an ABI 3130xL or ABI3500xLDx sequencing apparatus (Applied Biosystem). Additional 46 patients were screened for mutations in the CYP2U1, DDHD2 and GBA2 genes in a pilot experiment of amplicon-based high-throughput pooled-sequencing performed by using a Fluidigm Access Array System (Fluidigm Corporation, San Francisco, CA, USA) for amplicon generation followed by the Nextera technology (Illumina, San 
Diego, CA, USA) for targeted resequencing, using a MiSeq apparatus (Illumina). Sets of primers used to amplify the genomic fragments containing all coding exons of the three genes through the Fluidigm technology are in a supplementary file. Technical details for targeted NGS experiments are provided as an Online Resource. Briefly, $93 \%$ of the NGS fragments for each gene had coverage of at least 399 reads and passed quality control. The remaining $7 \%$ that did not pass the quality control were re-sequenced by Sanger sequencing. Variants detected were validated by Sanger sequencing.

All variants were checked against a panel of 600 Italian controls and against the dbSNP and 1,000 genome database. Mutation nomenclature is according to the recommendations of the Human Genome Variation Society and refers to the published CYP2U1, DDHD2 and GBA2 cDNA sequences (Acc. NM_183075.2, NM_015214.2 and NM_020944.2, respectively) with nucleotide ?1 corresponding to the A of the ATG translation initiation codon. Missense changes were analysed for possible pathogenic effects on protein function by using different prediction software (MutPred, SIFT, SNAP, PhD-SNP, SNPs\&GO, Panther and Provean).

\section{Results}

\section{Genetic findings}

One hundred and fifty patients were screened for CYP2U1 and DDHD2 genes; 46 of these patients were additionally screened for GBA2 mutations. This work led to the identification of three families carrying a mutation (Table 1), one for each of three genes. A mutation in CYP2U1 affecting the ATG codon (c.1A[C, p.Met1?) was found in patient P574 (Fig. 1). As a consequence, a putative truncated protein missing the first 209 amino acid residues is predicted to be synthesized starting from the next in-frame ATG located 628 bases downstream. This mutation was inherited by both parents.

The index patient of family P1242 was found to carry a homozygous base change in exon 16 of DDHD2 gene, c.1978G [C, p.Asp660His (Fig. 1) previously described in a compound heterozygous state in another family [8]. This mutation, inherited by both parents, segregated also in the affected sister (Fig. 1).

A pilot experiment of amplicon-based high-throughput pooled-sequencing led to the identification of a single homozygous mutation in exon 13 of the GBA2 gene, c.2048G [C, p.Gly683Arg, in the proband of family P922. The sequence change inherited from the parents, segregated in the two proband's brothers with subclinical signs of the disease. The Gly683 mutant residue is evolutionary conserved and falls within the glucosylceramidase domain of the GBA2 protein, just upstream from the transmembrane domain (residues 689-708) [16]. This change is predicted to be either deleterious/damaging or disease found by the software used (see "Methods").

The missense changes here identified in the three genes were checked against a panel of 600 controls, the dbSNP and the 1,000 genome database.

\section{Clinical findings}

Clinical and radiological features of the three families with mutations are summarised in Table 1 while detailed clinical description is provided as an Online Resource. Overall, the CYP2U1-mutated patient presents an early-onset pure/ mildly complicated form of the diseases, with subclinical signs of neuropathy, without sensory deficits or intellectual disability with normal MRI. The DDHD2 mutated patients display clinical and neuroradiological (Fig. 2) features partly overlapping the SPG11 subtype with a more severe phenotype and an earlier onset. The GBA2 family includes a pair of dizygotic twins and a third brother, overall displaying a phenotype characterized by spasticity, mild cerebellar signs and moderate eyelid ptosis with a different degree of severity in the proband (severe spasticity, difficulty in walking and frequent falls) with respect to the two brothers (evidence of clinical signs only at neurological examination).

\section{Discussion}

CYP2U1, DDHD2 and GBA2 genes are associated with early-onset complicated forms of HSP with a variable degree of mental impairment and TCC at the MRI [7, 8, 10]. GBA2 was also found mutated in a recessive form of ataxia with neuropathy and spasticity [11].

Mental impairment and TCC at the MRI are more consistently present in the DDHD2-related subtype (SPG54) with respect to the CYP2U1 one, SPG56 (previously referred as SPG49) [7, 8].

The SPG56 subtype shows indeed a wide range of variability with a mix of complicated and pure forms of disease with early-onset (from birth to age 8) [7]. SPG56 complicated patients frequently show spasticity at the upper limbs, rare dystonic postures, cognitive alteration and subclinical neuropathy mainly at the lower limbs. At the neuroradiology level, TCC and WMA may be present [7]. Analogously, in SPG54, the first symptoms of spasticity appear at age 2 frequently preceded by a psychomotor delay that develops into intellectual disability [8]. Signs of spasticity at the upper limbs, dysarthria and dysphagia are frequently observed. Brain MRI reveals a 
Table 1 Clinical Features of the patients carrying the DDHD2, CYP2U1 or GBA2 mutations

\begin{tabular}{|c|c|c|c|c|c|c|}
\hline Patient & P1242 II-1 & P1242 II-2 & P574 & P922 II-1 & P922 II-2 & P922 II-3 \\
\hline Mutation & \multicolumn{2}{|c|}{ DDHD2 c.1978G[C, p.Asp660His } & $\begin{array}{l}\text { CYP2U1 c.1A[C, } \\
\text { p.Met1? }\end{array}$ & \multicolumn{3}{|c|}{ GBA2 c.2048G[C, p.Gly683Arg } \\
\hline Consanguinity & No & & Yes & Yes & & \\
\hline $\begin{array}{l}\text { Age at onset }(\mathrm{y}) / \\
\text { symptoms at } \\
\text { onset }\end{array}$ & $\begin{array}{l}3 \text { months/distal } \\
\text { movements, } \\
\text { myoclonus like }\end{array}$ & $\begin{array}{l}18 \text { months/ } \\
\text { developmental } \\
\text { delay }\end{array}$ & $\begin{array}{l}18 \text { months/ } \\
\text { developmental } \\
\text { delay }\end{array}$ & $\begin{array}{l}\text { 10/gait } \\
\text { impairment }\end{array}$ & No symptoms & No symptoms \\
\hline $\begin{array}{l}\text { Disease duration/ } \\
\text { years }\end{array}$ & 15 & 21 & 3 & 14 & l & l \\
\hline $\begin{array}{l}\text { Disability score } \\
(\mathrm{n} / 7)\end{array}$ & 4 & 6 & 5 & 3 & 1 & 1 \\
\hline LL spasticity & Moderate-severe & Severe & Severe & Severe & Moderate & No \\
\hline LL reflexes & Brisk & Brisk Ankle clonus & $\begin{array}{l}\text { Brisk/Polikinetic } \\
\text { ankle clonus }\end{array}$ & $\begin{array}{l}\text { Brisk, ankle } \\
\text { clonus }\end{array}$ & $\begin{array}{l}\text { Brisk, ankle } \\
\text { clonus }\end{array}$ & $\begin{array}{l}\text { Brisk, ankle } \\
\text { clonus }\end{array}$ \\
\hline LL weakness & Mild & Severe & Moderate & Mild & - & - \\
\hline LL amyotrophy & Mild distal & Moderate distal & - & Mild distal & - & - \\
\hline Babinski sign & $?$ & $?$ & $?$ & $\begin{array}{l}? \text { on the right } \\
\text { side }\end{array}$ & - & - \\
\hline UL spasticity & Mild & Mild-moderate & - & Moderate & - & - \\
\hline UL reflexes & Brisk & Brisk & Slightly Brisk & Brisk & Brisk & Brisk \\
\hline UL weakness & Mild & Mild-moderate & $\begin{array}{l}\text { Slight clumsiness of } \\
\text { distal fine } \\
\text { movements }\end{array}$ & - & - & - \\
\hline UL amyotrophy & Mild distal & Mild distal & - & - & - & - \\
\hline Dysarthria & $?$ & $?$ & - & - & - & - \\
\hline $\begin{array}{l}\text { Superficial } \\
\text { sensory } \\
\text { abnormalities }\end{array}$ & - & - & - & - & - & - \\
\hline $\begin{array}{l}\text { Deep sensory } \\
\text { abnormalities }\end{array}$ & Not evaluable & Not evaluable & Not evaluable & - & - & - \\
\hline $\begin{array}{r}\text { Pes cavus/ } \\
\text { scoliosis }\end{array}$ & $-/ ?$ & $-/ ?$ & Kyphosis & Flatfoot/- & $-1-$ & Flatfoot/- \\
\hline $\begin{array}{l}\text { Urinary } \\
\text { symptoms }\end{array}$ & - & $\begin{array}{l}\text { Sphinteric control } \\
\text { never acquired }\end{array}$ & - & $\begin{array}{l}\text { Urinary } \\
\text { incontinence }\end{array}$ & - & - \\
\hline Mental status & Mental retardation & Mental retardation & $\begin{array}{l}\text { Normal, except for } \\
\text { expressive } \\
\text { language delay }\end{array}$ & Normal & Normal & Normal \\
\hline $\begin{array}{l}\text { Ataxia/other } \\
\text { cerebellar signs }\end{array}$ & $?$ & $?$ & - & Mild dysmetria & Mild dysmetria & Mild dysmetria \\
\hline $\begin{array}{l}\text { Eye movement } \\
\text { abnormalities }\end{array}$ & Absent & Absent & - & Eyelid ptosis & $\begin{array}{l}\text { Left eyelid } \\
\text { ptosis }\end{array}$ & Eyelid ptosis \\
\hline Visual acuity & Normal & Normal & Normal & Mildly reduced & Normal & Normal \\
\hline Cerebral MRI & $\begin{array}{l}\text { TCC PWMH } \\
\text { (periventricular } \\
\text { white-matter } \\
\text { hyperintensities) } \\
\text { Global WM } \\
\text { reduction }\end{array}$ & $\begin{array}{l}\text { TCC PWMH Mild } \\
\text { cerebellar atrophy- } \\
\text { mild brainstem } \\
\text { atrophy }\end{array}$ & Normal & Normal & NA & NA \\
\hline ENMG & Normal & $\begin{array}{l}\text { Mild reduction of } \\
\text { motor nerve } \\
\text { velocity }\end{array}$ & $\begin{array}{l}\text { Slight chronic } \\
\text { neurogenic signs at } \\
\text { needle } \\
\text { electromyography, } \\
\text { normal conduction } \\
\text { studies }\end{array}$ & Normal & NA & NA \\
\hline
\end{tabular}


Table 1 continued

\begin{tabular}{lllllll}
\hline Patient & P1242 II-1 & P1242 II-2 & P574 & P922 II-1 & P922 II-2 & P922 II-3 \\
\hline Other & $\begin{array}{c}\text { Behavioural } \\
\text { disturbances- }\end{array}$ & Cognitive decline & - & - & $\begin{array}{c}\text { Positive } \\
\text { Hoffman sign }\end{array}$ & $\begin{array}{c}\text { Positive } \\
\text { Hoffman sign }\end{array}$ \\
\hline
\end{tabular}

LL lower limbs, UL upper limbs, ENMG elechtroneuromyography, NA Not Available, TCC Thin corpus callosum

? present, - absent

Disability assessed on a 7 point scale [12]: 1, minimal disability (slight stiffness of the legs); 2, mild disability (unable to run, but full autonomy): 3 , moderate disability when walking (reduced perimeter, frequent falls); 4, severe disability (unilateral support required to walk); 5 , bilateral support required to walk; 6 , wheelchair bound; 7 , bedridden. Table data refer to the last clinical evaluation

Fig. 1 The Pedigrees of familial cases carrying CYP2U1, DDHD2 and GBA2 mutations. Diamond symbols are for anonymity reasons; black and white symbols indicate affected and healthy subjects, respectively. Arrows indicate the probands. Electropherograms of the mutations identified in the study. The mutant nucleotides are boxed. Partial alignment of the amino acid sequences encompassing the protein regions carrying the mutant residues is shown below
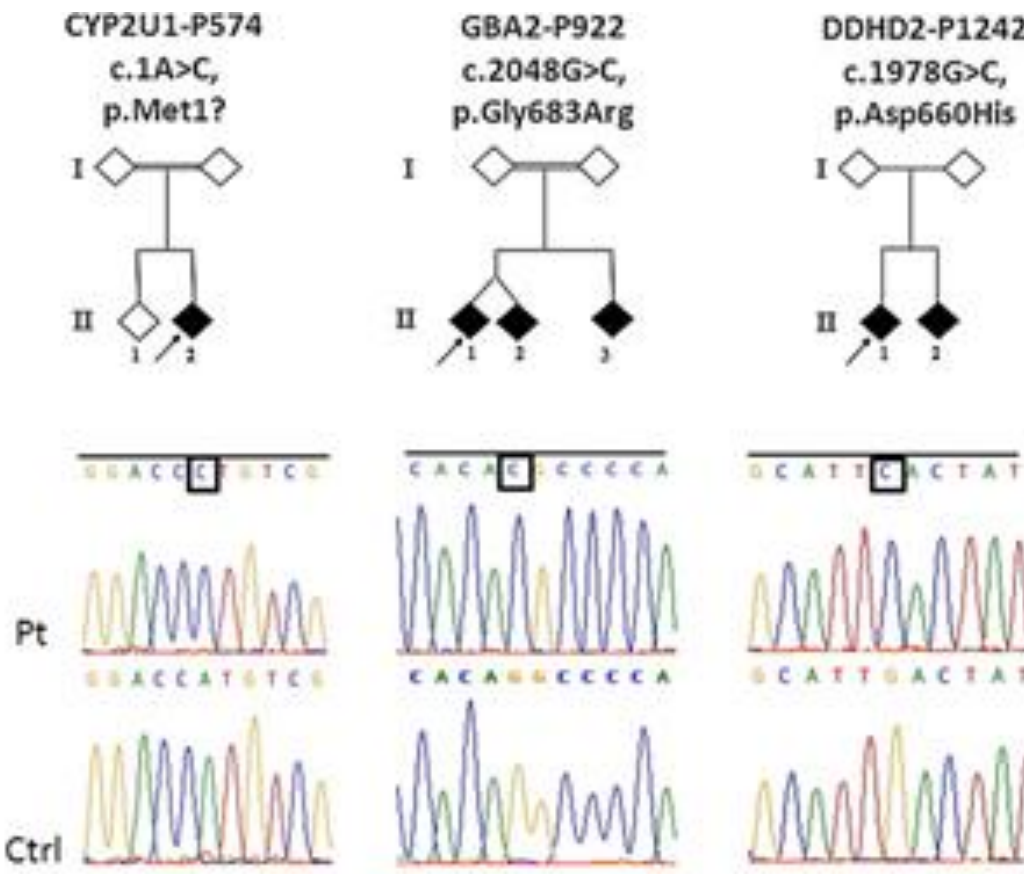

I

II

GBA2-P922

c. $2048 \mathrm{G}>C$,

p.Gly683Arg

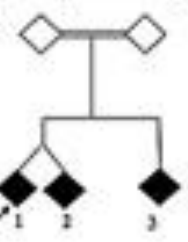

DHD2-P1242

C.1978G>C,

p.Asp660His
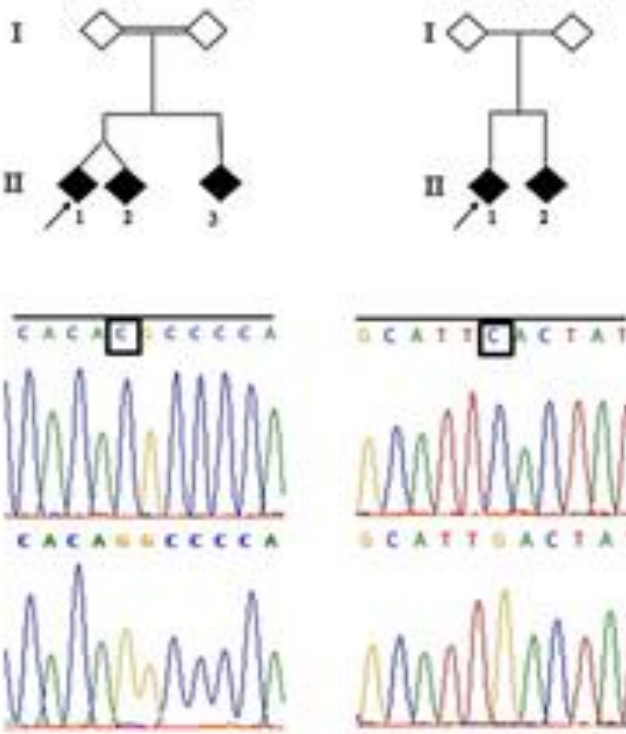
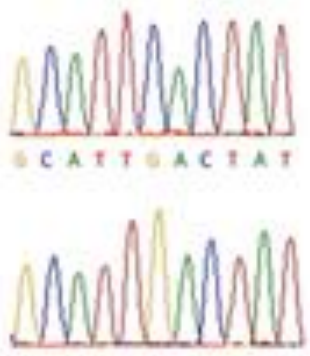

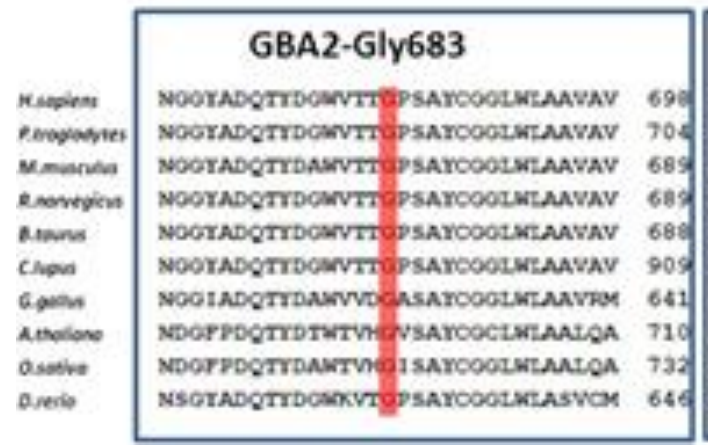

\begin{tabular}{|c|c|}
\hline DDHD2-Asp 660 & \\
\hline 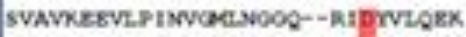 & 666 \\
\hline 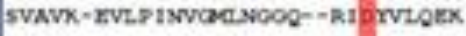 & 665 \\
\hline 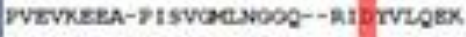 & 654 \\
\hline 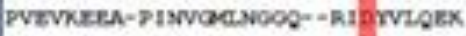 & 657 \\
\hline 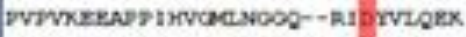 & 663 \\
\hline 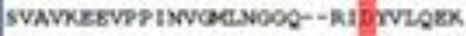 & 670 \\
\hline 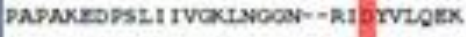 & 6.42 \\
\hline 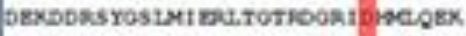 & 836 \\
\hline 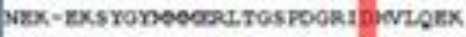 & 84) \\
\hline 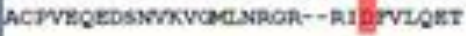 & 676 \\
\hline
\end{tabular}

consistent pattern of abnormalities including TCC and a variable degree of periventricular hyperintensities [8].

The families carrying mutations identified in this screening P574 (CYP2U1) and P1242 (DDHD2) show features largely overlapping with the described SPG56 and SPG54 phenotypes, respectively. Nevertheless, in the family with the
DDHD2 mutation, the presence of behavioural abnormalities and attention deficits in one of the affected sibs was not reported so far. Short stature, which was reported as one of the key feature of DDHD2-related HSP [17], is not observed in this family. Based on the clinical features observed, the SPG54 subtype, although overlapping with SPG11, shows an overall 
Fig. 2 MRI of the patient carrying the DDHD2 mutation. Sagittal T1-weighted (a), coronal T2-weighted (b) and axial T2-weighted (c, d) and FLAIR (e) sections. A markedly thin corpus callosum is evident on sagittal section (arrow). The overall volume of the white matter is reduced. T2-weighted and FLAIR images show a subtle hyper-intense signal bilaterally in peritrigonal white matter and centrum semiovale (arrowheads)
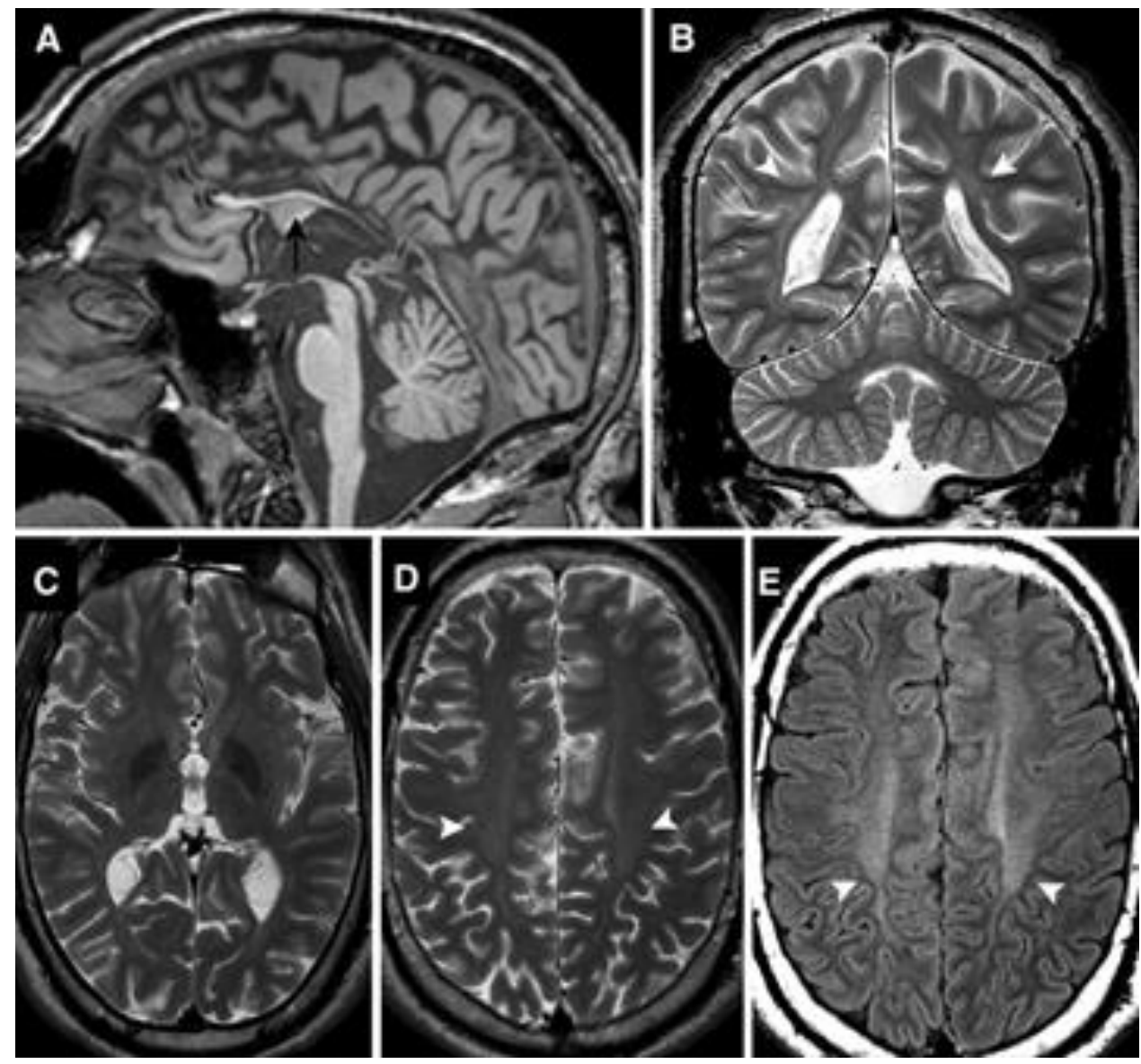

more severe clinical presentation and an earlier age of symptoms onset. The DDHD2 homozygous mutation here identified c.1978G L C (p.Asp660His) was already reported in a compound heterozygous state in another family [8].The mutation falls within the DDHD domain of the DDHDdomain-containing 2 (DDHD2) protein which belongs to the mammalian intracellular phospholipase A1 ( PLA $_{1}$ ) family. Members of this family exhibit enzymatic activity and hydrolyse the acyl-group of phospholipids in the sn-1 position and share a conserved lipase motif $(\mathrm{GxSxG})$ and a DDHD domain. This multifunctional domain along with the sterilealpha-motif (SAM) is essential for the phospholipase activity of the DDHD2 protein [18]. It is possible that DDHD2 plays a role by facilitating membrane and vesicle fusion through phospholipid hydrolysis. Therefore, the pathogenicity of the p.Asp660His mutation affecting a highly conserved residue in the DDHD domain likely relies on its effect on the phospholipid hydrolysis activity and, therefore, on membrane fusion and/or vesicle trafficking as previously suggested [8, 17].

The phenotype of the patient with the CYP2U1 mutation overlaps the reported SPG56 phenotype. The patient indeed shows a mildly complicated form of the diseases, with only subclinical signs of neuropathy at the lower limbs and slight involvement of the upper limbs without sensory deficits. From the cognitive point of view, he shows only an expressive language delay. Based on disease presentation (see the Online resource) and on the Egyptian origin of the consanguineous family, the patient was first diagnosed as a possible Infantile Ascending Spastic Paraparesis (IAHSP) or a Juvenile Primary Lateral Sclerosis (JPLS). Although at present, genetic findings along with disease evolution indicate a classical form of spastic paraparesis, the identification of a CYP2U1 mutation in P574 suggests the opportunity to perform the CYP2U1 genetic screening in very young patients with early-onset pure/mildly complicated HSP, with a suspect of IAHSP/JPLS who had tested negative for ALS2, SPG3A and SPG4 mutations. This can, thus, facilitate the mutation search in such cases, even at the time of disease presentation, without waiting for disease evolution.

The mutation identified in CYP2U1 is a novel mutation disrupting the initiation codon of the protein c.1A $\mathbf{C}$, p.Met1? Assuming that a putative truncated protein could still be expressed by the mutant cells, this would lack the first 209 of the 544 amino acid residues of the wild type protein. Therefore, the mutation eliminates about half of 
the highly conserved cytochrome P450 functional domain, thus leading to a likely loss of protein function. CYP2U1 encodes a P450 hydroxylase catalysing the in vitro hydroxylation of arachidonic acid and related long-chain fatty acids, which are mediators of signalling pathways and may affect signalling of hormones and neurotransmitters [7].

Affected members of the family with the GBA2 mutation (P922) show variable phenotype severity ranging from severe spasticity with impaired gait in the proband to slight unrecognized impairment in his two brothers. The clinical picture is mainly overlapping the SPG46 subtype of paraparesis (pyramidal tract involvement at the onset and predominance of the pyramidal signs in the disease course) with few clinical aspects reminding one of the GBA2related recessive ataxia picture.

Indeed SPG46 and the recessive form of cerebellar ataxia with neuropathy and spasticity, both associated with mutations in GBA2 gene, are quite overlapping and show differences in the initial disease presentation. Gait abnormalities due to the insidious appearance of stiffness and weakness in the lower extremities are the presenting symptoms in the majority of the SPG46 patients described so far $[10,19]$. With disease progression cerebellar ataxia, neuropathy, cataract and mild to moderate intellectual disability with cerebral, cerebellar and corpus callosum atrophy at the MRI are observed [10]. By contrast, progressive cerebellar ataxia associated with cerebellar dysarthria characterizes the initial clinical presentation of all GBA2-related recessive ataxia patients described so far [11]. A pyramidal syndrome associated with axonal sensory and sensory-motor neuropathy is then developed by all patients [11].

Differently from SPG46, none of the patients from the P922 family shows signs of cataract or hypogonadism and, differently from both the SPG46 and the GBA2-related recessive ataxia picture, none of them had evidence of peripheral neuropathy, at least at this early stage of the disease. Similarly to the already described cases of recessive ataxia, the MRI of P922 proband is normal.

The GBA2 mutation shared by the three brothers, p.Gly683Arg, falls within the glucosylceramidase domain of the protein, the non-lysosomal b-glucosidase 2 enzyme, catalysing the conversion of glucosylceramide to free glucose and ceramide as well as the reverse reaction consisting in the transfer of glucose to different lipid substrates $[20,21]$. The location of the missense variant, the high evolutionary conservation of the affected residue, the software's predictions and the variant segregation within the family all together point toward a functional relevance of the p.Gly683Arg missense change to the pathogenesis. On a different level, GBA2 enzyme activity was recently biochemically redefined along with its pharmacological control by imino-sugars, [22]; therefore, GBA2 mutation findings are instrumental to the characterization of the pathophysiological role of the enzyme in view of a putative pharmacological treatment of this form of disease.

In conclusion, this is the first large study confirming the phenotypes associated with mutations in either CYP2U1 or DDHD2 genes while identifying a novel intermediate GBA2-related phenotype overlapping the two clinical entities, SPG46 and the recessive ataxia so far described. The intermediate phenotype presented by this patient is in line with the wide clinical overlap among complicated HSP with cerebellar component, the spastic ataxias and some recessive ataxia syndromes.

However, the common genetic background of the SPG46 subtype and the GBA2-related recessive ataxia syndrome [11] provides an objective explanation to the overlap observed in these two clinical entities. Variable accumulation of glucosylceramides in the endoplasmic reticulum of neuronal cells as one of the postulated consequences of GBA2 loss of function, thus leading to a change in calcium homeostasis and neuronal degeneration [11], may reasonably account for the clinical heterogeneity and overlap observed between the two syndromes.

The results of the screening indicate also that SPG56, SPG54 and SPG46 subtypes of paraparesis are not commonly represented in a general population of patients with complicated HSP, variable degree of mental impairment and a heterogeneous pattern of brain MRI abnormalities. Indeed the mutation frequency observed is less than $1 \%$ for either CYP2U1 or DDHD2 genes (1/150 mutated patient in either of the two cases) and close to $2 \%$ for GBA2 (1/46 mutated patient). Although these figures may change depending upon population type, size and origin, the general indication is a low mutation frequency. On the other hand, these data underline once again the impressive genetic heterogeneity characterizing the group of complicated spastic paraparesis with intellectual disability that still needs to be fully dissected.

Web resources

1000genome database http://browser.1000genomes.org/ index.html.

NCBI dbSNP http://www.ncbi.nlm.nih.gov/SNP/.

SIFT and Provean http://sift.jcvi.org/.

MutPred http://mutpred.mutdb.org/.

SNAP https://rostlab.org/services/SNAP/.

PhD-SNP http://snps.biofold.org/phd-snp/phd-snp.html.

SNPs\&GO http://snps-and-go.biocomp.unibo.it/snpsand-go/.

Panther http://www.pantherdb.org/tools/csnpScore

Form.jsp? 
Acknowledgments The authors wish to thank the patients and their families for participation to this work, and all referring clinicians for collaboration. The work was supported by funds from the Ministry of Health, Grant \# RC2012-2013 and 5xMille.

Ethical standards All human studies have been approved by the appropriate ethics committee and have, therefore, been performed in accordance with the ethical standards laid down in 1964 Declaration of Helsinki and its later amendments. All persons gave their informed consent prior to their inclusion in the study. We have not included any details that might disclose the identity of the subjects in the study.

Conflicts of interest On behalf of all the authors, the corresponding author states that there is no conflict of interest.

\section{References}

1. Fink JK (2006) Hereditary spastic paraplegia. Curr Neurol Neurosci Rep 6(1):65-76

2. Depienne C, Stevanin G, Brice A, Durr A (2007) Hereditary spastic paraplegias: an update. Curr Opin Neurol 20(6):674-680. doi:10.1097/WCO.0b013e3282f190ba

3. Fink JK (2013) Hereditary spastic paraplegia: clinico-pathologic features and emerging molecular mechanisms. Acta Neuropathol 126(3):307-328. doi:10.1007/s00401-013-1115-8

4. McDermott C, White K, Bushby K, Shaw P (2000) Hereditary spastic paraparesis: a review of new developments. J Neurol Neurosurg Psychiatry 69(2):150-160. doi:10.1136/jnnp.69.2.150

5. Boukhris A, Stevanin G, Feki I, Denora P, Elleuch N, Miladi MI, Goizet C, Truchetto J, Belal S, Brice A, Mhiri C (2009) Tunisian hereditary spastic paraplegias: clinical variability supported by genetic heterogeneity. Clin Genet 75(6):527-536. doi:10.1111/j. 1399-0004.2009.01176.x

6. Finsterer J, Löscher W, Quasthoff S, Wanschitz J, Auer-Grumbach M, Stevanin G (2012) Hereditary spastic paraplegias with autosomal dominant, recessive, $\mathrm{X}$-linked, or maternal trait of inheritance. J Neurol Sci 318(1-2):1-18. doi:10.1016/j.jns.2012. 03.025

7. Tesson C, Nawara M, Salih MA, Rossignol R, Zaki MS, Al Balwi M, Schule R, Mignot C, Obre E, Bouhouche A, Santorelli FM, Durand CM, Oteyza AC, El-Hachimi KH, Al Drees A, Bouslam N, Lamari F, Elmalik SA, Kabiraj MM, Seidahmed MZ, Esteves T, Gaussen M, Monin ML, Gyapay G, Lechner D, Gonzalez M, Depienne C, Mochel F, Lavie J, Schols L, Lacombe D, Yahyaoui M, Al Abdulkareem I, Zuchner S, Yamashita A, Benomar A, Goizet C, Durr A, Gleeson JG, Darios F, Brice A, Stevanin G (2012) Alteration of fatty-acid-metabolizing enzymes affects mitochondrial form and function in hereditary spastic paraplegia. Am J Hum Genet 91(6):1051-1064. doi:10.1016/j.ajhg.2012.11.001

8. Schuurs-Hoeijmakers JH, Geraghty MT, Kamsteeg EJ, BenSalem S, de Bot ST, Nijhof B, van de Vondervoort II, van der Graaf M, Nobau AC, Otte-Höller I, Vermeer S, Smith AC, Humphreys P, Schwartzentruber J; FORGE Canada Consortium, Ali BR, Al-Yahyaee SA, Tariq S, Pramathan T, Bayoumi R, Kremer HP, van de Warrenburg BP, van den Akker WM, Gilissen C, Veltman JA, Janssen IM, Vulto-van Silfhout AT, van der Velde-Visser S, Lefeber DJ, Diekstra A, Erasmus CE, Willemsen MA, Vissers LE, Lammens M, van Bokhoven H, Brunner HG, Wevers RA, Schenck A, Al-Gazali L, de Vries BB, de Brouwer AP (2012) Mutations in DDHD2, encoding an intracellular phospholipase A (1), cause a recessive form of complex hereditary spastic paraplegia. Am J Hum Genet 91(6):1073-1081. doi:10.1016/j.ajhg.2012.10.017
9. Oz-Levi D, Ben-Zeev B, Ruzzo EK, Hitomi Y, Gelman A, Pelak K, Anikster Y, Reznik-Wolf H, Bar-Joseph I, Olender T, Alkelai A, Weiss M, Ben-Asher E, Ge D, Shianna KV, Elazar Z, Goldstein DB, Pras E, Lancet D (2012) Mutation in TECPR2 reveals a role for autophagy in hereditary spastic paraparesis. Am J Hum Genet 91(6):1065-1072. doi:10.1016/j.ajhg.2012.09.015

10. Martin E, Schüle R, Smets K, Rastetter A, Boukhris A, Loureiro JL, Gonzalez MA, Mundwiller E, Deconinck T, Wessner M, Jornea L, Oteyza AC, Durr A, Martin JJ, Schöls L, Mhiri C, Lamari F, Züchner S, De Jonghe P, Kabashi E, Brice A, Stevanin G (2013) Loss of function of glucocerebrosidase GBA2 is responsible for motor neuron defects in hereditary spastic paraplegia. Am J Hum Genet 92(2):238-244. doi:10.1016/j.ajhg. 2012.11.021

11. Hammer MB, Eleuch-Fayache G, Schottlaender LV, Nehdi H, Gibbs JR, Arepalli SK, Chong SB, Hernandez DG, Sailer A, Liu G, Mistry PK, Cai H, Shrader G, Sassi C, Bouhlal Y, Houlden H, Hentati F, Amouri R, Singleton AB (2013) Mutations in GBA2 cause autosomal-recessive cerebellar ataxia with spasticity. Am J Hum Genet 92(2):245-251. doi:10.1016/j.ajhg.2012.12.012

12. Goizet C, Boukhris A, Maltete D, Guyant-Maréchal L, Truchetto J, Mundwiller E, Hanein S, Jonveaux P, Roelens F, Loureiro J, Godet E, Forlani S, Melki J, Auer-Grumbach M, Fernandez JC, Martin-Hardy P, Sibon I, Sole G, Orignac I, Mhiri C, Coutinho P, Durr A, Brice A, Stevanin G (2009) SPG15 is the second most common cause of hereditary spastic paraplegia with thin corpus callosum. Neurology 73(14):1111-1119. doi:10.1212/WNL. 0b013e3181bacf59

13. Schüle R, Schlipf N, Synofzik M, Klebe S, Klimpe S, Hehr U, Winner B, Lindig T, Dotzer A, Riess O, Winkler J, Schöls L, Bauer P (2009) Frequency and phenotype of SPG11 and SPG15 in complicated hereditary spastic paraplegia. J Neurol Neurosurg Psychiatry 80(12):1402-1404. doi:10.1136/jnnp.2008.167528

14. Schule R, Schöls L (2011) Genetics of hereditary spastic paraplegias. Semin Neurol 31(5):484-493. doi:10.1055/s-00311299787

15. Harding AE (1983) Classification of the hereditary ataxias and paraplegias. Lancet 1(8334):1151-1155. doi:10.1016/S01406736(83)92879-9

16. Körschen HG, Yildiz Y, Raju DN, Schonauer S, Bönigk W, Jansen V, Kremmer E, Kaupp UB, Wachten D (2013) The non-lysosomal b-glucosidase GBA2 is a non-integral membrane-associated protein at the endoplasmic reticulum (ER) and Golgi. J Biol Chem 288(5):3381-3393. doi:10.1074/jbc. M112.414714

17. Gonzalez M, Nampoothiri S, Kornblum C, Oteyza AC, Walter J, Konidari I, Hulme W, Speziani F, Schols L, Zuchner S, Schule R (2013) Mutations in phospholipase DDHD2 cause autosomal recessive hereditary spastic paraplegia (SPG54). Eur J Hum Genet 21(11):1214-1218. doi:10.1038/ejhg.2013.29

18. Inoue H, Baba T, Sato S, Ohtsuki R, Takemori A, Watanabe T, Tagaya M (1823) Tani K (2012) Roles of SAM and DDHD domains in mammalian intracellular phospholipase A1 KIAA0725p. Biochim Biophys Acta 4:930-939. doi:10.1016/j. bbamcr.2012.02.002

19. Boukhris A, Feki I, Elleuch N, Miladi MI, Boland-Auge A, Truchetto J, Mundwiller E, Jezequel N, Zelenika D, Mhiri C, Brice A, Stevanin G (2010) A new locus (SPG46) maps to 9p21.2-q21.12 in a Tunisian family with a complicated autosomal recessive hereditary spastic paraplegia with mental impairment and thin corpus callosum. Neurogenetics 11(4):441-448. doi:10. 1007/s10048-010-0249-2

20. Boot RG, Verhoek M, Donker-Koopman W, Strijland A, van Marle J, Overkleeft HS, Wennekes T (2007) Identification of the non-lysosomal glucosylceramidase as beta-glucosidase 2. J Biol Chem 282(2):1305-1312. doi:10.1074/jbc.M610544200 
21. Yildiz Y, Matern H, Thompson B, Allegood JC, Warren RL, Ramirez DM, Hammer RE, Hamra FK, Matern S, Russell DW (2006) Mutation of beta-glucosidase 2 causes glycolipid storage disease and impaired male fertility. J Clin Invest 116(11):2985-2994. doi:10.1172/JCI29224
22. Ridley CM, Thur KE, Shanahan J, Thillaiappan NB, Shen A, Uhl K, Walden CM, Rahim AA, Waddington SN, Platt FM, van der Spoel AC (2013) b-Glucosidase 2 (GBA2) activity and imino sugar pharmacology. J Biol Chem 288:26052-26066. doi:10 1074/jbc.M113.463562 